\title{
Chimeric antigen receptor T (CAR-T) cells expanded with IL-7/IL-15 mediate superior antitumor effects
}

\section{Dear Editor,}

Genetic engineering of $\mathrm{T}$ cells to express chimeric antigen receptors (CARs) is an efficient approach for clinical therapy of hematological malignancies (Kuwana et al., 1987; Eshhar et al., 1993; Barrett et al., 2014). The CARs endow T cells with the ability to recognize specific antigens and bind them in an MHC-independent manner, thereby overcoming some of the mechanisms that mediate tumor immune escape. In addition, by providing co-stimulatory signals, CARs endow $T$ cells with enhanced cytotoxicity and persistence compared with primary T cells. A typical CAR comprises a single-chain variable fragment (scFv) derived from a monoclonal antibody $(\mathrm{mAb})$ for antigen recognition and signaling domains for coactivation (Eshhar et al., 1993; Sadelain et al., 2013).

To date, CAR-T cell therapy has been most effective in immunotherapy of $\mathrm{CD} 19^{+} \mathrm{B}$ cell acute lymphoblastic leukemia, with a complete response in more than $75 \%$ of cases (Sadelain et al., 2013). However, there are still some challenges for CAR-T-mediated treatments. Side effects like offtargeting, cytokine release syndrome (CRS) and neuronal toxicities have been reported, and these may induce lethal responses (Morgan et al., 2010; Park et al., 2011). In addition, no response, incomplete tumor regression, and tumor recurrence were also observed after CAR-T treatment. For example, $10 \%-20 \%$ of patients were non-responsive to CD19 CAR-T clinical therapy (Lee et al., 2015; Park et al., 2018). Even in cases with a complete response, about $50 \%$ of them suffered tumor recurrence in one year, and one third of them had a CD19 ${ }^{+}$relapse (Maude et al., 2018; Orlando et al., 2018). These disappointing results are associated with early CAR-T cell disappearance or poor cell function, which leads to incomplete tumor regression or loss of long-term antitumor effects.

Cytokines are important factors for T cell development and homeostasis. In addition to the TCR and costimulatory receptors, cytokines provide stimulatory signals for full $\mathrm{T}$ cell activation, and have pleiotropic effects on T cell proliferation, differentiation and function. Currently, IL-2 is the main cytokine used to culture cells for adoptive cell therapy, as it plays an important role in the proliferation and functional effect of $T$ cells. However, T cells cultured with IL-2 are phenotypically heterogeneous, being predominantly composed of effector memory cells which have sufficient functional effect but are sensitive to death.

IL-7 has a critical role in the development and maturation of $T$ cells. It promotes the generation of naïve and central memory $T$ cell subsets and regulates their homeostasis. IL15 mediates the formation and homeostasis of CD8 memory T cells. It has been reported that IL-7 and IL-15 are able to instruct $\mathrm{T}$ cells toward memory stem-like phenotypes, which are less differentiated and have a superior capacity for expansion and survival (Cieri et al., 2013). Here, we systematically compared the effects of IL-7/IL-15 and IL-2 on the expansion, apoptosis and anti-tumor responses of CAR-T cells.

We first constructed the anti-CD19 CAR (19BB-CAR) using an anti-CD19 mAb (clone FMC63)-derived scFv linked to the $C D 8 \alpha$ hinge and transmembrane regions, followed by a $4-1 B B$ intracellular signaling domain and the $C D 3 \zeta$ signaling moiety. The 19BB-CAR and enhanced green fluorescent protein (eGFP) sequences were ligated and subcloned into the lentiviral vector FUW with a substitutive EF1a promoter (Fig. S1A). The cultured primary T cells were stimulated with anti-CD3/anti-CD28 Dynabeads and cytokine IL-2 before transduction with 19BB-CAR lentiviral particles. Using Protein $L$ binding to the variable immunoglobulin light chains of the CAR, we found that CAR expression is directly correlated to eGFP expression (Fig. S1B). The CAR was highly expressed in IL-2-cultured T cells three days after infection (Fig. S1C). The CAR-T cells were expanded 100 -fold in 2 weeks under IL-2 stimulation (Fig. S1D).

To test the specificity of 19BB-CAR-T cells, we co-incubated them with two human leukemia cell lines, Raji $\left(C D 19^{+}\right)$ and K562 (CD19-). The secretion of IL-2, IFN-Y and TNF- $\alpha$ by 19BB-CAR-T cells was significantly increased upon coincubation with $\mathrm{CD}_{19^{+}}$Raji but not $\mathrm{CD}_{19^{-}} \mathrm{K} 562$ cells (Fig. S1E). Accordingly, cytotoxicity assays showed that 19BB-CAR-T cells specifically lysed $\mathrm{CD}^{+} 9^{+}$Raji but not CD19- K562 cells (Fig. S1F). These data suggest that 19BBCAR-T cells specifically recognize the CD19 molecule. 
To evaluate the anti-tumor effects of 19BB-CAR-T cells cultured using IL-2 in vivo, CD19 ${ }^{+}$Raji cells labeled with fluorescent luciferase fusion protein were engrafted to immunodeficient mice for lymphoma formation. Then human T cells transduced with 19BB-CAR or GFP vectors were infused into the mice (Fig. S1G). Mice receiving 19BB-CAR$T$ cells showed effective tumor regression, while mice infused with T cells harboring empty vector had progressive tumor growth (Fig. S1G-H). Long-term monitoring showed that mice infused with 19BB-CAR-T cells had a significantly higher survival rate and longer survival period compared with mice receiving empty-vector $\mathrm{T}$ cells (Fig. S1I). These data provide evidence that 19BB-CAR-T cells can effectively remove tumor cells in vivo. However, lymphoma recurrence was observed in some mice treated with 19BB-CAR-T cells, and nearly half of the 19BB-CAR-T mice died within 60 days of infusion due to the tumor burden. These phenotypes are consistent with clinical data, which calls for optimization of CAR-T cells for more efficient tumor killing.

Proliferation and apoptosis are two major aspects to be considered for in vitro expansion of CAR-T cells. In the twoweek in vitro culture assays, we found that the 19BB-CAR-T cells were more efficiently expanded with IL-7/IL-15 than with IL-2 (Fig. 1A). Satisfactorily, there were no differences in the CAR transduction efficiency of T cells cultured in IL-2 or IL-7/IL-15 (Fig. S2). 19BB-CAR-T cells cultured with IL-7/IL15 showed higher proliferation and a lower apoptosis rate compared to cells cultured with IL-2 (Fig. 1B and 1C). Consistent with this phenotype, the expression of the antiapoptosis protein BCL-2 is higher in 19BB-CAR-T cells cultured with IL-7/IL-15 than with IL-2 (Fig. 1D). Together, these data suggest that IL-7/IL-15 provide a better environment than IL-2 for CAR-T cell expansion.

We next investigated the functional properties of CAR-T cells expanded in IL-7/IL-15 or IL-2. The results showed no significant difference in immune cytokine release (IL-2, IFN$\mathrm{Y}, \mathrm{TNF}-\alpha$ ) or specific lysis (Fig. $1 \mathrm{E}$ and $1 \mathrm{~F}$ ). We also investigated the cytokine secretion and cytotoxicity of 19BB-CAR$\mathrm{T}$ cells after serial antigen stimulation to mimic tumor encounter in vivo, and found no significant differences between the two culture systems (Fig. S3A-C).

We then infused the IL-7/IL-15- or IL-2-expanded 19BBCAR-T cells into mice with lymphoma for detection of tumor suppression effects. The antitumor effects were similar in the first 3 weeks. However, the 19BB-CAR-T cells expanded in IL-7/IL-15 showed superior anti-tumor activity, and the longterm survival of the tumor burden mice was significantly improved (Fig. 1G-I).

According to their surface expression of CD45RA and CD62 L, primary $T$ cells are divided into four differentiation states: naïve T cells $\left(T_{N}\right)\left(C D 45 R A^{+} C D 62 L^{+}\right)$, central memory $T$ cells $\left(T_{C M}\right)\left(C D 45 R^{-} \mathrm{CD}^{-} 2^{+}\right)$, effector memory T cells $\left(\mathrm{T}_{\mathrm{EM}}\right)\left(\mathrm{CD} 45 \mathrm{RA}^{-} \mathrm{CD} 2 \mathrm{~L}^{-}\right)$, and CD45RA ${ }^{+}$effector memory $\mathrm{T}$ cells ( $\mathrm{T}_{\mathrm{RAEM}}$ ) (CD45RA ${ }^{+} \mathrm{CD} \mathrm{CL}^{-}$) as reported (Cieri et al., 2013). We found that $C D 8^{+}$CAR-T cell expansion was enhanced during culture with IL-7/IL-15 (Fig. 2A). IL-7/IL-15
Figure 1. IL-7/IL-15 supplements induce increased proliferation of 19BB-CAR-T cells and mediate superior anti-tumor effects in vivo. (A) Ex vivo proliferation of 19BB-CAR-T cells following stimulation with anti-CD3/ CD28 antibodies and cytokines IL-7/IL-15 or IL-2. The results are from 4 independent experiments, ${ }^{\star \star} P<0.01$. (B) CytoTell Blue staining to detect the proliferation of 19BB-CAR-T cells cultured with IL-7/IL-15 or IL-2 at day 11. The results are from 4 independent experiments, ${ }^{*} P<$ 0.05. (C) 19BB-CAR-T cells cultured with IL-7/IL-15 have a lower apoptosis rate than cells cultured with IL-2. Annexin $\mathrm{V}$ and $\mathrm{PI}$ were used to determine the proportion of apoptotic cells after a two-week culture. Data are shown as mean \pm SEM from 3 independent experiments. ${ }^{*} P<$ 0.05. (D) 19BB-CAR-T cells cultured with IL-7/IL-15 show increased expression of the anti-apoptosis protein BCL-2 compared to cells cultured with IL-2. Cells were cultured with IL-7/IL-15 or IL-2 for 11 days and then analyzed by flow cytometry using anti-BCL-2 antibody. (E) ELISA detection of IL-2, IFN- $y$ and TNF- $\alpha$ secretion by 19BBCAR-T cells expanded with IL-7/IL-15 or IL-2. The cells were stimulated by Raji or K562 cells for 24 hours. Data are presented as mean \pm SEM from 3 independent experiments. ns, not significant. (F) 19BB-CAR-T cells expanded with IL-7/IL-15 or IL-2 have similar cytotoxicity. Data are presented as mean \pm SEM from 3 independent experiments. (G) Representative images of Raji/LUC tumor regression in mice treated for 4 weeks with19BBCAR-T cells expanded with IL-7/IL-15 or IL-2, $n=4$ per group. (H) Mean photon flux \pm SEM of bioluminescent signals in mice receiving infusions of 19BB-CAR-T cells expanded with IL-7/IL-15 or IL-2. Data are from 3 independent experiments, $n=4$ per group. (I) Survival curves of mice receiving 19BB-CAR-T cells expanded with IL-7/IL-15 or IL-2. Data are from 3 independent experiments, $n=4$ per group. ${ }^{*} P<0.05$ (IL-7/IL-15 vs. IL-2).

induced an increase of the $\mathrm{CD}^{+}$naïve $\mathrm{T}$ cell and central memory $T$ cell populations, while IL-2 enhanced the $C D 8^{+}$ effector memory $T$ cell population in vitro (Fig. $2 B-C)$. These data indicate that IL-7/IL-15-expanded 19BB-CAR-T cells, which have undergone limited differentiation, may engraft into tumor-bearing mice more efficiently.

Chemokine receptor CCR7 is involved in lymph-node homing of $\mathrm{T}_{\mathrm{N}}$ and $\mathrm{T}_{\mathrm{CM}}$ cells, as well as lymph-node migration of dendritic cells. The expression levels of chemokine receptors CCR7 and CXCR4 are higher in 19BB-CAR-T cells expanded in IL-7/IL-15 than in IL-2 (Figs. 2D and S4). Accordingly, in a gradient of chemokine CCL21, 19BB-CAR$T$ cells cultured in IL-7/IL-15 showed enhanced migration ability compared to cells cultured in IL-2 (Fig. 2E).

Regulatory $T$ (Treg) cells play an important role in immunosuppression. We found that IL-2 mediated a smaller increase of the CD4 $4^{+}$Foxp $^{+}$19BB-CAR-T cell population 


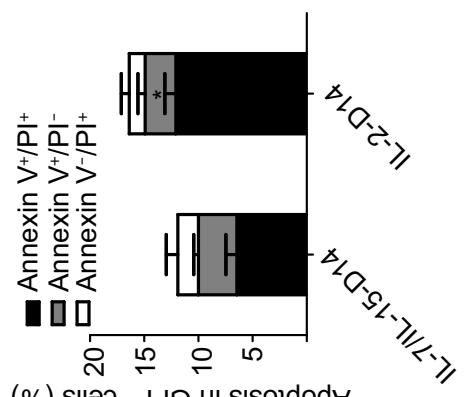

(\%) s॥əo +d $\unlhd \supset$ u! s!soldod $\forall$

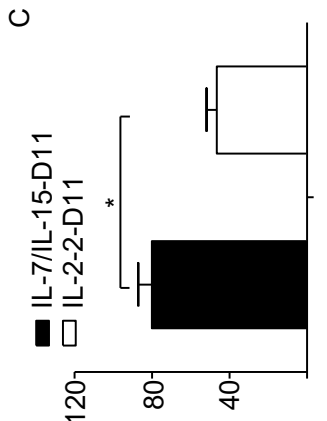

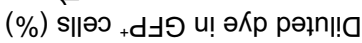
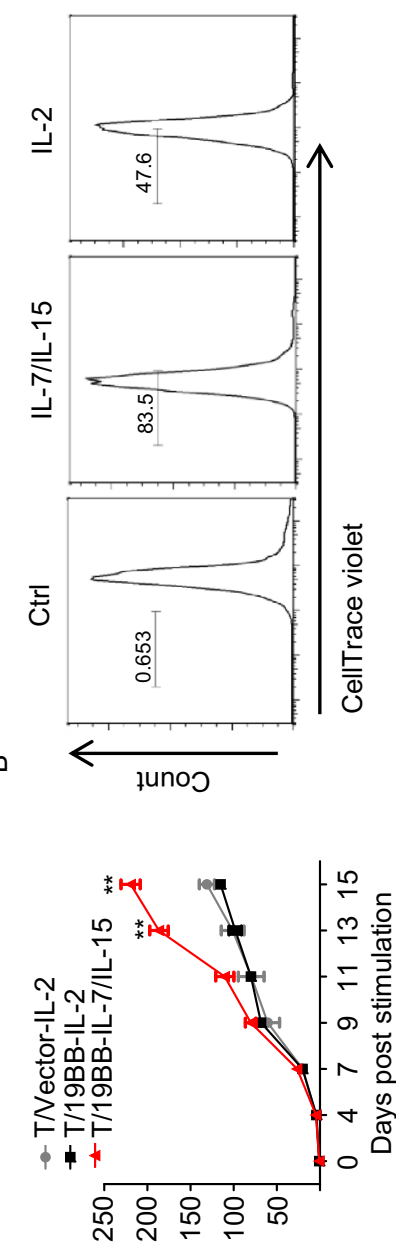

$\varangle$ $\left.{ }_{9} \mathrm{O} L_{*}\right)$ słunos \|əว +d

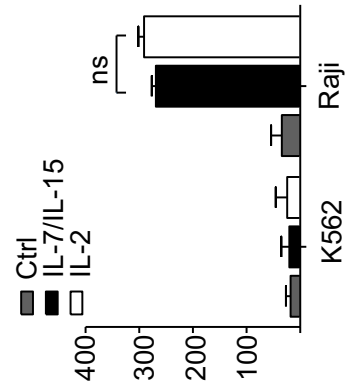

(ךm/6d) uo!̣əגวәs $\mathrm{D}-\unlhd \mathrm{N} \perp$

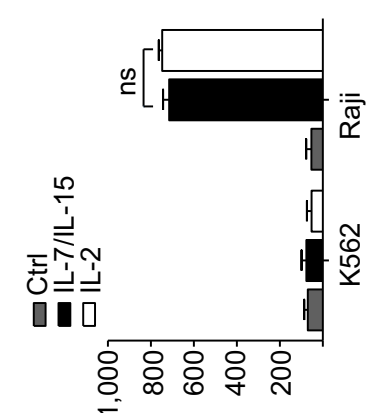

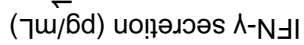

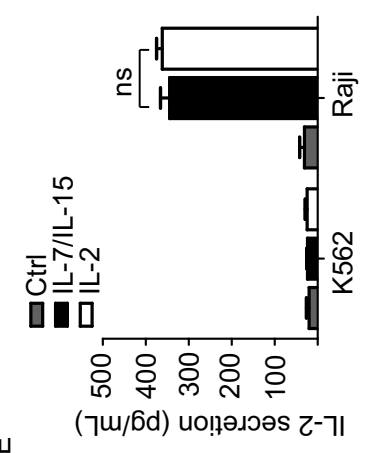

ш

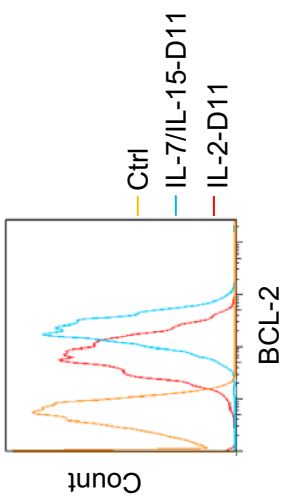

๑
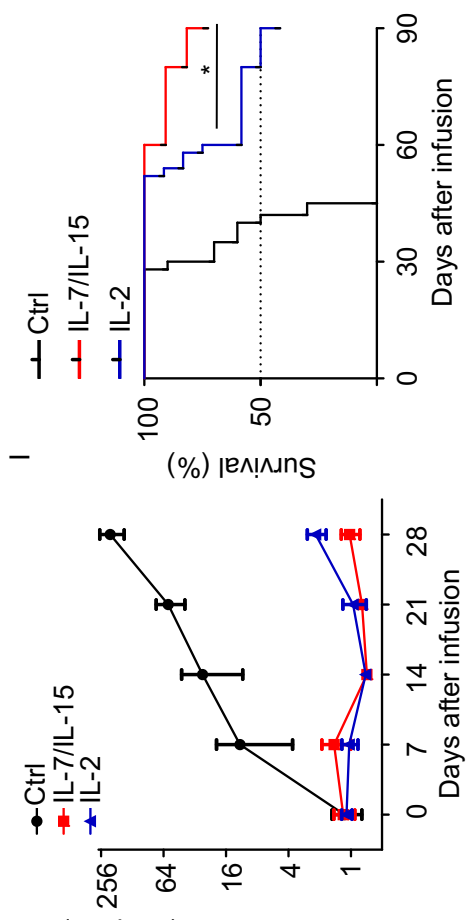

I $\left(\mathrm{s} / 4 \mathrm{~d}_{9} \mathrm{Ol}\right)$ əวuəวsəu!un|!

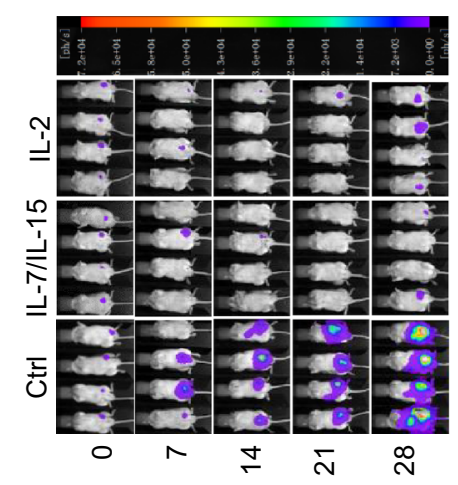

( ) - uo!snu! дәңе sкea -

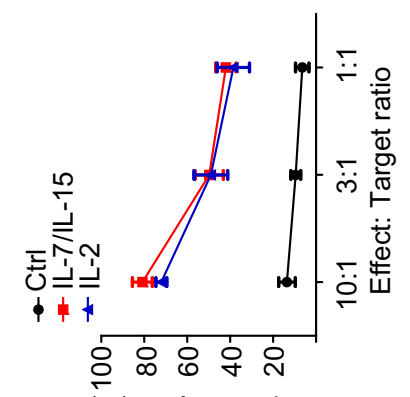

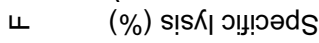




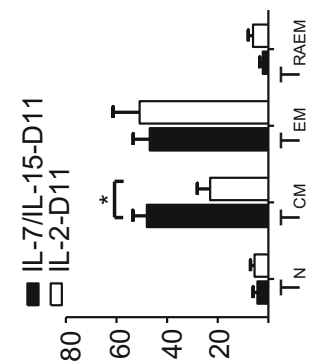

$(\%) s \| ə 0+9 \exists \rho_{+}+\nabla 0 \supset$

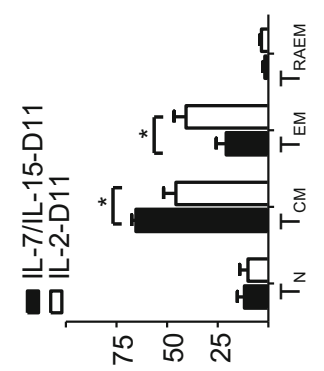

u

$(\%) s \| ə 0+9 \exists \supset+800$

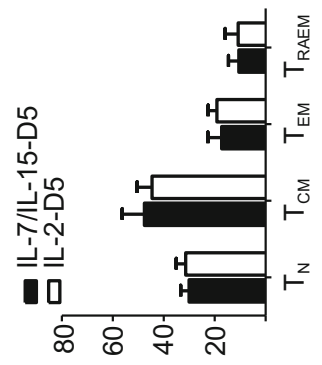

$(\%) s \| ə 0+d \exists \partial_{+}+$

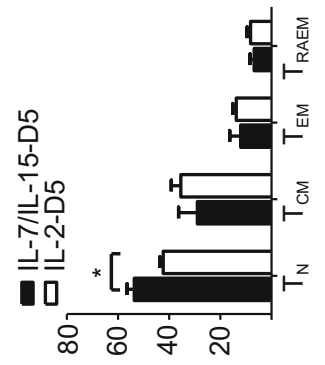

$\infty$
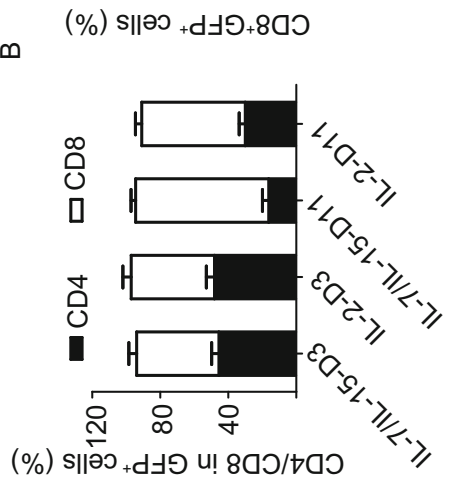
$\varangle$

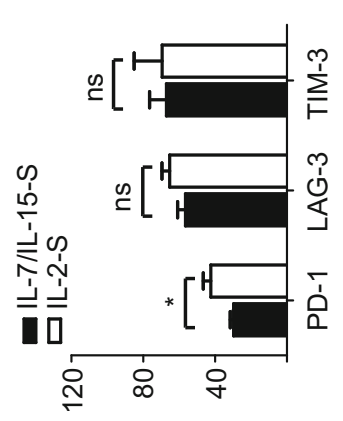

(\%) s\|əว +dปכ u! uo!̣ssəıdx

0

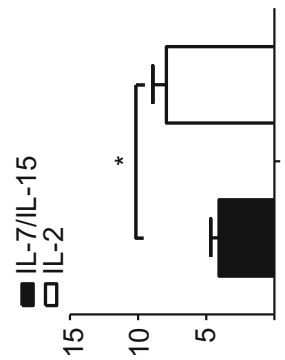

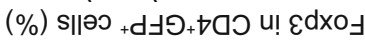

ᄂ

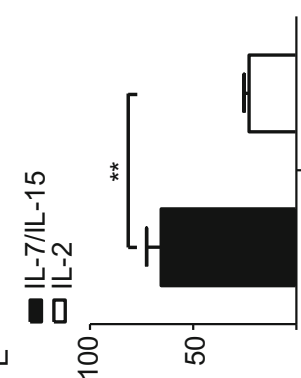

(\%) uo!̣eı6!w

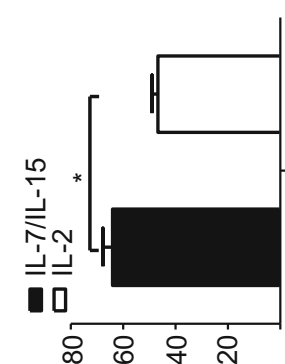

(\%) s॥əว +dヨつ u! Lบวว

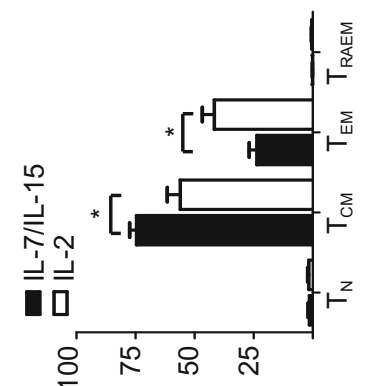

(\%) $s|| ə 0_{+} d \exists O_{+} 800^{2}$

$x$

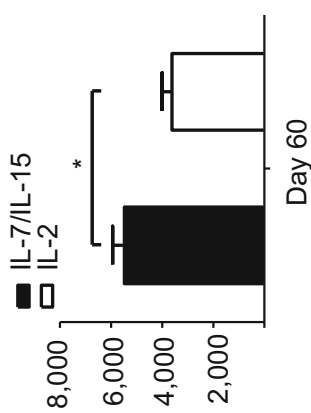

$\neg \quad \forall N a 6 r /$ soḷdoJ

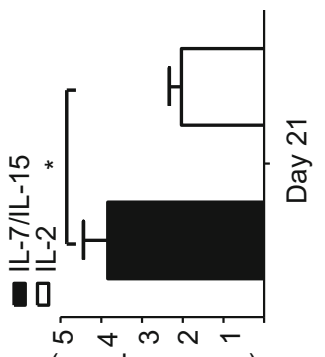

(uәә|ds/s||ə弓, ${ }_{9} \mathrm{Ol}$ )

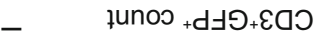

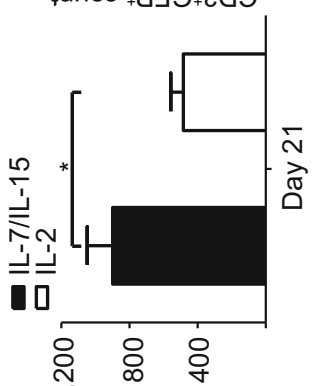

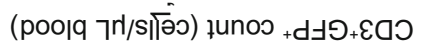

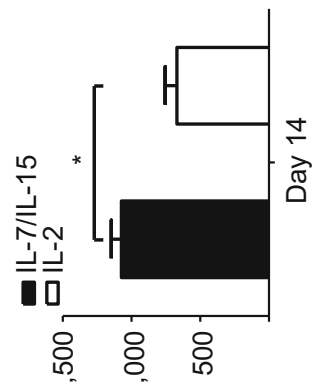

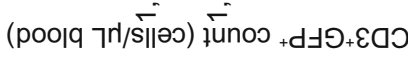


Figure 2. 19BB-CAR-T cells cultured with IL-7/IL-15 show a superior antitumor phenotype in vitro and enhanced grafting efficiency after infusion into tumor-bearing mice. (A) 19BB-CAR-T cells cultured with IL-7/IL-15 generate a higher percentage of $\mathrm{CD}^{+}$T cells compared to cells cultured with IL-2. Bars show the distribution of CD4 ${ }^{+}$and CD8 ${ }^{+}$T cells in 19BB-CAR-T cells cultured with IL-7/IL-15 or IL-2 at day 3 (D3) and day 11 (D11). Data are presented as mean \pm SEM from 4 independent experiments. (B) 19BB-CAR-T cells cultured with IL-7/IL-15 generate a higher percentage of CD8 ${ }^{+}$naïve cells $\left(\mathrm{T}_{\mathrm{N}}\right)$ compared to cells cultured with IL-2. Expression of CD45RA and CD62L was assessed by flow cytometry analysis of 19BB-CAR-T cells cultured with IL-7/IL-15 or IL2 at day 5 (D5). The percentages of $\mathrm{T}_{\mathrm{N}}\left(\mathrm{CD} 45 \mathrm{RA}^{+} \mathrm{CD} 62 \mathrm{~L}^{+}\right), \mathrm{T}_{\mathrm{CM}}\left(\mathrm{CD} 45 \mathrm{RA}^{-} \mathrm{CD} 62 \mathrm{~L}^{+}\right), \mathrm{T}_{\mathrm{EM}}\left(\mathrm{CD} 45 \mathrm{RA}^{-} \mathrm{CD} 6 \mathrm{~L}^{-}\right)$, and $\mathrm{T}_{\mathrm{RAEM}}$ $\left(\mathrm{CD} 45 \mathrm{RA}^{+} \mathrm{CD} 62 \mathrm{~L}^{-}\right)$in $\mathrm{CD}^{+}$lymphocytes (left) and $\mathrm{CD}^{+}$lymphocytes (right) are shown. Results are presented as mean $\pm \mathrm{SEM}$ from 4 independent experiments, ${ }^{*} P<0.05$. (C) 19BB-CAR-T cells expanded with IL-7/IL-15 generate a larger population of central memory $T$ cells during culture. The percentages of $\mathrm{T}_{\mathrm{N}}\left(\mathrm{CD} 45 \mathrm{RA}^{+} \mathrm{CD} 62 \mathrm{~L}^{+}\right), \mathrm{T}_{\mathrm{CM}}\left(\mathrm{CD} 45 \mathrm{RA} \mathrm{A}^{-} \mathrm{CD} 62 \mathrm{~L}^{+}\right), \mathrm{T}_{\mathrm{EM}}\left(\mathrm{CD} 45 \mathrm{RA}^{-} \mathrm{CD} 62 \mathrm{~L}^{-}\right)$, and $\mathrm{T}_{\text {RAEM }}\left(\mathrm{CD} 45 \mathrm{RA}^{+} \mathrm{CD} 2 \mathrm{~L}^{-}\right.$) in $\mathrm{CD}^{+}$lymphocytes (left) and CD4 ${ }^{+}$lymphocytes (right) in 19BB-CAR-T cells cultured with IL-7/IL-15 or IL-2 at day 11 are shown. Data are presented as mean \pm SEM from 4 independent experiments, ${ }^{*} P<0.05$. (D) IL-7/IL-15 enhance CCR7 expression compared to IL-2. The expression of CCR7 on 19BB-CAR-T cells cultured with IL-7/IL-15 or IL-2 at day 11 was detected by flow cytometry. Results are presented as mean \pm SEM from 4 independent experiments, ${ }^{*} P<0.05$. (E) 19BB-CAR-T cells cultured with IL-7/IL-15 show higher migration ability compared to cells cultured with IL-2. Results are presented as mean \pm SEM from 3 independent experiments, ${ }^{*} P<0.01$. (F) IL-7/IL-15 decreases the Foxp $3^{+}$CD4 ${ }^{+}$T cell population. The expression of Foxp3 in 19BBCAR-T cells cultured with IL-7/IL-15 or IL-2 at day 11 was detected by flow cytometry. Results are shown as mean \pm SEM from 4 independent experiments, ${ }^{*} P<0.05$. (G) The percentage of 19BB-CAR-T cells expressing the inhibitory receptor PD- 1 is lower after culture with IL-7/IL-15 than with IL-2. The expression of PD-1, LAG-3 and TIM-3 on 19BB-CAR-T cells cultured with IL-7/IL-15 or IL-2 was determined by flow cytometry. Results are presented as mean \pm SEM from 3 independent experiments, ${ }^{\star} P<0.05$. (H) IL-7/IL-15 increase the survival rate of 19BB-CAR-T cells in peripheral blood of tumor-bearing mice. $\mathrm{CD}^{+} \mathrm{GFP}^{+}$cells were detected in peripheral blood by flow cytometry in lymphoma-bearing mice at days 14 and 21 after infusion. Results are presented as mean \pm SEM from 5 independent experiments, ${ }^{*} P<0.05$. (I) IL-7/LL-15 enhance survival of 19BB-CAR-T cells in spleen of tumor-bearing mice after infusion. $\mathrm{CD}^{+} \mathrm{GFP}^{+}$cells were detected by flow cytometry in the spleen of lymphoma-bearing mice at day 21 after infusion. Results are shown as mean \pm SEM from 5 independent experiments, ${ }^{*} P<0.05$. (J) Copy numbers of 19BB-CAR vector per microgram genomic DNA in the peripheral blood of mice receiving 19BB-CAR-T cells at day 60 after infusion. Results are shown as mean \pm SEM from 4 independent experiments, ${ }^{*} P<0.05$. (K) IL-7/LL-15 maintain the CD8 ${ }^{+} \mathrm{T}_{\mathrm{CM}}\left(\mathrm{CD} 45 \mathrm{RA}^{-} \mathrm{CD} 62 \mathrm{~L}^{+}\right)$population in 19BB-CAR-T cells from peripheral blood in tumor-bearing mice. Flow cytometry results are presented as mean \pm SEM from 4 independent experiments, ${ }^{\star} P<0.05$.

than IL-7/IL-15 during in vitro expansion of T cells (Fig. 2F). In addition, we found decreased expression of PD-1 in 19BB-CAR-T cells cultured in IL-7/IL-15 compared to IL-2 upon serial antigen stimulation by Raji cells, which indicates that IL-7/IL-15 decrease CAR-T cell exhaustion (Fig. 2G). These data provide supporting evidence that IL-7/L-15 induce a superior anti-tumor activity in 19BB-CAR-T cells compared to IL-2.

We further evaluated the survival and memory $T$ cell phenotype of 19BB-CAR-T cells cultured with different cytokines after infusion into tumor-bearing mice. 19BB-CART cells cultured with IL-7/L-15 showed enhanced engraftment in mice compared to cells cultured with IL-2 (Fig. $2 \mathrm{H}-$ J). After infusion into mice, 19BB-CAR-T cells cultured in IL7/IL-15 generated more $\mathrm{CD} 8^{+}$central memory $T$ cells than CAR-T cells treated with IL-2, while cells cultured in IL-2 generated more $\mathrm{CD}^{+}$effector memory $\mathrm{T}$ cells than cells cultured in IL-7/IL-15 (Fig. 2K). This is consistent with the in vitro results. These data provide evidence that CAR-T cells cultured in IL-7/IL-15 have superior anti-tumor activity in vivo.

Generating optimized CAR-T cells in vitro is an important strategy to enhance the clinical efficacy of CAR-T cells in cancer immunotherapy. Recently, Xu et al. reported that IL-7/ IL-15 are better than IL-2 for preserving the
$\mathrm{CD}^{+}{ }^{+} \mathrm{CD} 45 \mathrm{RA}^{+} \mathrm{CCR} 7^{+}$population in ex vivo-cultured CAR-T cells, and endow the CAR-T cells with superior proliferation and survival capability upon serial antigen stimulation (Xu et al., 2014). Another study showed that IL-7/IL-15 instruct the expansion of $\mathrm{CD} 62 \mathrm{~L}^{+} \mathrm{CD} 45 \mathrm{RA}^{+}$memory $\mathrm{T}$ cells from naïve precursors (Cieri et al., 2013). In contrast, we found that IL-7/IL-15 promotes CAR-T cell proliferation directly without antigen stimulation in vitro, and the level of apoptosis is low. CAR-T cells cultured with IL-7/IL-15 expanded around 2-fold more within two weeks than cells cultured with IL-2, which will favor the generation of CAR-T cells for certain patients whose lymphocytes have limited expansion ability.

In conclusion, we systematically compared the effects of IL-7/IL-15 and IL-2 on CAR-T cell culture, and demonstrated that CAR-T cells expanded in the presence of IL-7/IL-15 showed enhanced proliferation and superior antitumor activity. IL-7/L-15 selectively expanded naïve and central memory T cells, which help CAR-T cell engraftment in tumorbearing mice. Apart from IL-2, IL-7 and IL-15, many other cytokines are important for T cell development, differentiation and function. IL-12 is involved in the differentiation of naïve Th0 cells into Th1 cells, and augments the activity of cytotoxic $\mathrm{T}$ cells. IL-18 regulates the immune response by enhancing the secretion of IFN- $\mathrm{Y}$ and augmenting cytolytic 
activity. These cytokines could be potentially investigated for optimization of CAR-T expansion.

\section{FOOTNOTES}

This work was supported by grants from the National Key R\&D Program of China 2018YFA0108402, the Strategic Priority Research Program of the Chinese Academy of Sciences XDA16030302, the National Natural Science Foundation of China Program 31720103907, 31570995, 31621004, and the National Thousand Young Talents Program to T.Z. We sincerely thank Dr. Haoyi Wang for providing the FUW vector as a gift.

The authors declare no conflicts of interests.

All procedures followed were in accordance with the ethical standards of the Ethical Committee on Human Experimentation of the Institute of Zoology, Chinese Academy of Sciences, and with the Helsinki Declaration of 1975, as revised in 2000 (5).

All animal studies were carried out under protocols approved by the Institutional Animal Care and Use Committee.

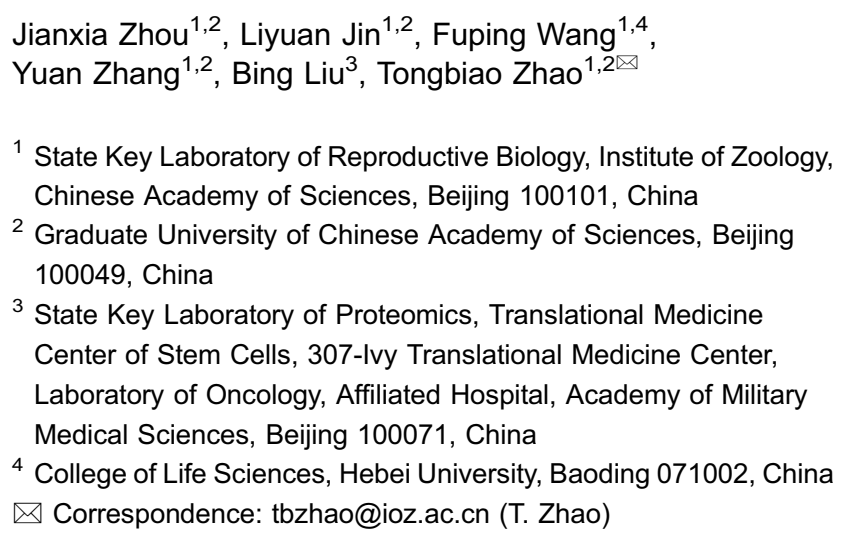

${ }^{2}$ Graduate University of Chinese Academy of Sciences, Beijing 100049, China

${ }^{3}$ State Key Laboratory of Proteomics, Translational Medicine Center of Stem Cells, 307-Ivy Translational Medicine Center, Laboratory of Oncology, Affiliated Hospital, Academy of Military Medical Sciences, Beijing 100071, China

${ }^{4}$ College of Life Sciences, Hebei University, Baoding 071002, China $\bowtie$ Correspondence: tbzhao@ioz.ac.cn (T. Zhao)

\section{OPEN ACCESS}

This article is distributed under the terms of the Creative Commons Attribution 4.0 International License (http://creativecommons.org/ licenses/by/4.0/), which permits unrestricted use, distribution, and reproduction in any medium, provided you give appropriate credit to the original author(s) and the source, provide a link to the Creative Commons license, and indicate if changes were made.

\section{REFERENCES}

Barrett DM, Singh N, Porter DL, Grupp SA, June CH (2014) Chimeric antigen receptor therapy for cancer. Annu Rev Med 65:333-347

Cieri N, Camisa B, Cocchiarella F, Forcato M, Oliveira G, Provasi E, Bondanza A, Bordignon C, Peccatori J, Ciceri F et al (2013) IL-7 and IL-15 instruct the generation of human memory stem T cells from naive precursors. Blood 121:573-584

Eshhar Z, Waks T, Gross G, Schindler DG (1993) Specific activation and targeting of cytotoxic lymphocytes through chimeric single chains consisting of antibody-binding domains and the gamma or zeta subunits of the immunoglobulin and T-cell receptors. Proc Natl Acad Sci U S A 90:720-724

Kuwana Y, Asakura Y, Utsunomiya N, Nakanishi M, Arata Y, Itoh S, Nagase F, Kurosawa $Y$ (1987) Expression of chimeric receptor composed of immunoglobulin-derived $\mathrm{V}$ regions and T-cell receptor-derived $\mathrm{C}$ regions. Biochem Biophys Res Commun 149:960-968

Lee DW, Kochenderfer JN, Stetler-Stevenson M, Cui YK, Delbrook C, Feldman SA, Fry TJ, Orentas R, Sabatino M, Shah NN et al (2015) T cells expressing CD19 chimeric antigen receptors for acute lymphoblastic leukaemia in children and young adults: a phase 1 dose-escalation trial. Lancet 385:517-528

Maude SL, Laetsch TW, Buechner J, Rives S, Boyer M, Bittencourt H, Bader P, Verneris MR, Stefanski HE, Myers GD et al (2018) Tisagenlecleucel in children and young adults with B-cell lymphoblastic leukemia. N Engl J Med 378:439-448

Morgan RA, Yang JC, Kitano M, Dudley ME, Laurencot CM, Rosenberg SA (2010) Case report of a serious adverse event following the administration of T cells transduced with a chimeric antigen receptor recognizing ERBB2. Mol Ther 18:843-851

Orlando EJ, Han X, Tribouley C, Wood PA, Leary RJ, Riester M, Levine JE, Qayed M, Grupp SA, Boyer M et al (2018) Genetic mechanisms of target antigen loss in CAR19 therapy of acute lymphoblastic leukemia. Nat Med 24:1504-1506

Park JH, Riviere I, Gonen M, Wang X, Senechal B, Curran KJ, Sauter C, Wang Y, Santomasso B, Mead E et al (2018) Long-term follow-up of CD19 CAR therapy in acute lymphoblastic leukemia. N Engl J Med 378:449-459

Park TS, Rosenberg SA, Morgan RA (2011) Treating cancer with genetically engineered T cells. Trends Biotechnol 29:550-557

Sadelain M, Brentjens R, Riviere I (2013) The basic principles of chimeric antigen receptor design. Cancer Discov 3:388-398

Xu Y, Zhang M, Ramos CA, Durett A, Liu E, Dakhova O, Liu H, Creighton CJ, Gee AP, Heslop HE et al (2014) Closely related T-memory stem cells correlate with in vivo expansion of CAR. CD19-T cells and are preserved by IL-7 and IL-15. Blood 123:3750-3759

Electronic supplementary material The online version of this article (https://doi.org/10.1007/s13238-019-0643-y) contains supplementary material, which is available to authorized users. 